OPEN ACCESS

Edited by:

Mingtao Zeng,

Texas Tech University Health Sciences

Center El Paso, United States

Reviewed by:

Rupsa Basu,

Helaina Inc., United States

Carolien Emma van de Sandt,

The University of Melbourne, Australia

${ }^{*}$ Correspondence:

Fan Zhou

fan.zhou@uib.no

Specialty section:

This article was submitted to

Vaccines and Molecular Therapeutics,

a section of the journal

Frontiers in Immunology

Received: 26 July 2021 Accepted: 05 November 2021 Published: 23 November 2021

Citation:

Zhou F, Hansen L, Pedersen G,

Grødeland $G$ and Cox R (2021)

Matrix M Adjuvanted H5N1 Vaccine Elicits Broadly Neutralizing Antibodies

and Neuraminidase Inhibiting

Antibodies in Humans That

Correlate With In Vivo Protection.

Front. Immunol. 12:747774.

doi: 10.3389/fimmu.2021.747774

\section{Matrix M Adjuvanted H5N1 Vaccine Elicits Broadly Neutralizing Antibodies and Neuraminidase Inhibiting Antibodies in Humans That Correlate With In Vivo Protection}

\author{
Fan Zhou $^{1 *}$, Lena Hansen ${ }^{1}$, Gabriel Pedersen ${ }^{1,2}$, Gunnveig Grødeland ${ }^{3}$ \\ and Rebecca Cox ${ }^{1,4}$ \\ 1 Influenza Center, Department of Clinical Science, University of Bergen, Bergen, Norway, ${ }^{2}$ Center for Vaccine Research, \\ Statens Serum Institut, Copenhagen, Denmark, ${ }^{3}$ Department of Immunology, University of Oslo and Oslo University Hospital, \\ Oslo, Norway, ${ }^{4}$ Department of Microbiology, Haukeland University Hospital, Bergen, Norway
}

The highly pathogenic avian influenza H5N1 viruses constantly evolve and give rise to novel variants that have caused widespread zoonotic outbreaks and sporadic human infections. Therefore, vaccines capable of eliciting broadly protective antibody responses are desired and under development. We here investigated the magnitude, kinetics and protective efficacy of the multi-faceted humoral immunity induced by vaccination in healthy adult volunteers with a Matrix $\mathrm{M}$ adjuvanted virosomal $\mathrm{H} 5 \mathrm{~N} 1$ vaccine. Vaccinees were given escalating doses of adjuvanted vaccine $(1.5 \mu \mathrm{g}, 7.5 \mu \mathrm{g}$, or $30 \mu \mathrm{g})$, or a nonadjuvanted vaccine $(30 \mu \mathrm{g})$. An evaluation of sera from vaccinees against pseudotyped viruses covering all (sub)clades isolated from human $\mathrm{H} 5 \mathrm{~N} 1$ infections demonstrated that the adjuvanted vaccines $(7.5 \mu \mathrm{g}$ and $30 \mu \mathrm{g})$ could elicit rapid and robust increases of broadly cross-neutralizing antibodies against all clades. In addition, the adjuvanted vaccines also induced multifaceted antibody responses including hemagglutinin stalk domain specific, neuraminidase inhibiting, and antibody-dependent cellular cytotoxicity inducing antibodies. The lower adjuvanted dose $(1.5 \mu \mathrm{g})$ showed delayed kinetics, whilst the non-adjuvanted vaccine induced overall lower levels of antibody responses. Importantly, we demonstrate that human sera post vaccination with the adjuvanted $(30 \mu \mathrm{g})$ vaccine provided full protection against a lethal homologous virus challenge in mice. Of note, when combining our data from mice and humans we identified the neutralizing and neuraminidase inhibiting antibody titers as correlates of in vivo protection.

Keywords: H5N1 (Avian influenza), correlate of protection, adjuvant, Matrix M, pseudotype neutralization, neuraminidase inhibiting antibodies 


\section{INTRODUCTION}

Enveloped RNA viruses, such as influenza viruses and coronaviruses, constantly evolve, thus causing zoonotic outbreaks and occasional pandemics in humans. Mutations accumulate over time and enable the virus to escape existing immunity established from previous infection and/or vaccination. This mechanism leads to the emergence of geographic and temporal novel variants, which hamper the effectiveness and efficacy of the vaccines designed based on ancestral viruses. As a result, vaccines targeting enveloped RNA viruses need to be updated at regular intervals. Vaccines capable of inducing broadly cross-protective immune responses are urgently needed.

Since its first isolation in 1996, the highly pathogenic avian influenza (HPAI) H5N1 virus have caused outbreaks in domestic and wild birds worldwide, as well as sporadic animal-human transmissions. To date, 862 human infections have been laboratory confirmed which resulting in 455 deaths (1). Tens of thousands of HPAI H5N1 virus strains have emerged in the last two decades. These variant strains are grouped into 10 clades and dozens of subclades according to the main surface glycoprotein hemagglutinin (HA) gene sequences. All the variants isolated from human infections are from clades $0,1,2$ and 7 (2-4). To combat the HPAI H5N1 viruses in situations of potential human-to-human transmission, a panel of prepandemic $\mathrm{H} 5 \mathrm{~N} 1$ vaccine candidates from each of the most common (sub)clades have been prepared (3). Different vaccines formats, including subunit, live attenuated, and adenoviral vectores have been tested in clinical trials alone, or in combination with adjuvants such as AS03 and MF59 (5-9). These vaccines elicited protective homologous antibody responses and low to moderate levels of neutralizing antibodies to closely related strains. However, the breadth of crossneutralizing antibody responses after vaccination has not been fully elucidated.

Compared to the highly variable HA head domain, HA stalk and neuraminidase (NA) are more conserved among circulating strains across different continents and seasons (10-12). Recent studies have revealed functions of non-neutralizing antibodies targeting these more conserved domains. For example, HA stalk specific antibodies can block viral genome release into the cytoplasm; whilst NA specific antibodies reduce progeny virion release from infected cells (13). In addition, non-neutralizing antibodies can trigger cytotoxicity and phagocytosis to clear infected cells $(14,15)$. However, whether these nonneutralizing antibodies correlate with in vivo protection against the highly pathogenic $\mathrm{H} 5 \mathrm{~N} 1$ virus remains unclear.

We have conducted a clinical trial with a virosomal H5N1 vaccine with Matrix M adjuvant in 60 adults. We have previously demonstrated that the adjuvanted $\mathrm{H} 5 \mathrm{~N} 1$ vaccines elicited potent vaccine specific neutralizing antibodies, and to a lesser extent cross-reactive hemagglutination inhibition (HI) antibodies and Th1 and Th2 CD4+ $\mathrm{T}$ cell responses against closely related strains (16-18). Here, we established an expanded panel of H5N1 pseudotypes covering all (sub)clades isolated from human infections; and characterized the kinetics and breadth of antibody responses after vaccination, including dissection of the multifaceted non-neutralizing antibody responses. We also assessed the in vivo protection from vaccine induced antibodies in a passive transfer murine model and investigated immunological candidates for correlates of protection.

\section{MATERIAL AND METHODS}

\section{Study Design}

Sixty healthy adult volunteers (20-49 years old) were enrolled in an open label phase I dose escalating clinical trial early 2009 at Haukeland University Hospital, Bergen, Norway (www. clinicaltrials.gov, NCT00868218) (16). The study was approved by the Regional Committee for Medical Research Ethics, Northern Norway and the Norwegian Medicines Agency. All participants provided written informed consent before inclusion into the study.

Participants were randomized into 4 groups, and intramuscularly vaccinated twice with the $\mathrm{H} 5 \mathrm{~N} 1$ virosomal vaccine (Crucell Berna

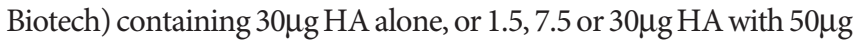
Matrix M adjuvant (Novavax) at 3-week interval (16). None of the participants had previously received an $\mathrm{H} 5 \mathrm{~N} 1$ vaccine.

\section{Vaccine and Sampling}

A monovalent inactivated virosomal $\mathrm{H} 5 \mathrm{~N} 1$ vaccine, containing vaccine strain NIBRG-14, a virus derived from A/Vietnam/1194/ 2004 (H5N1) and A/Puerto Rico/8/1934 (H1N1) using reverse genetics, was used in the clinical trial. The influenza surface antigens $\mathrm{HA}$ and NA were purified from beta-propiolactone (BPL) inactivated egg grown viruses, mixed with lecithin and incorporated into the phospholipid bilayer by spontaneous formation of the virosomes. The HA content of the vaccine was quantified by single radial diffusion, and the presence of NA was confirmed.

The adjuvant Matrix $M$ used in the trial was the $3^{\text {rd }}$ generation immune stimulating complex, which contains Matrix-A and Matrix-C fractions produced from purified Quillaja saponin fractions A and C, at the proportion of 91:9. The vaccine was formulated as $30 \mu \mathrm{g} \mathrm{HA}$ alone, or $1.5,7.5$ or

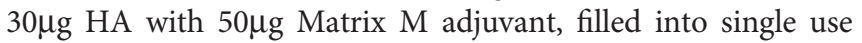
syringes, and stored at $4^{\circ} \mathrm{C}$ until use. All participants $(\mathrm{n}=60)$ received 2 doses of the vaccine at a 3-week interval, except one withdrawal from the $7.5 \mu \mathrm{g}$ HA adjuvanted vaccine group.

Blood samples were collected before, and up to 42 days after vaccination. Sera were separated, aliquoted and stored at $-80^{\circ} \mathrm{C}$ until use.

\section{Hemagglutination Inhibition Assay}

All sera were treated with receptor-destroying enzyme (RDE, Seiken) at a ratio of 1 in 4 at $37^{\circ} \mathrm{C}$ for $18 \mathrm{~h}$, and heat treated at $56^{\circ} \mathrm{C}$ for $1 \mathrm{~h}$. The treated sera were analysed in duplicate (2-fold serial dilution, starting from 1:10) with 4 hemagglutinating units of viruses and $0.8 \%$ horse red blood cells, as previously described $(16,17)$. A panel of reassortant $\mathrm{H} 5 \mathrm{~N} 1$ viruses were used, including A/Vietnam/1194/2004 (NIBRG-14, vaccine strain, 
clade 1), A/Indonesia/5/2005 (IBCDC-RG2, subclade 2.1.3.2), A/ turkey/Turkey/1/2005 (NIBRG-23, subclade 2.2.1), and A/ Cambodia/R0405050/2007 (NIBRG-88, subclade 1.1). The hemagglutination inhibition ( $\mathrm{HI}$ ) titer was determined as the reciprocal of the highest sera dilution giving 50\% inhibition of hemagglutination. Non-detected samples were assigned a value of 4 for calculation purpose.

\section{Pseudotype-Based Neutralization Assay}

$\mathrm{H} 5 \mathrm{~N} 1$ pseudotypes were generated by co-transfecting lentiviral vectors pHR'CMV-Luc, pCMVR 8 8.2, pCMVR-H5HA, and pCMVR-N1NA into HEK293T cells as previously described $(19,20)$. A panel of pCMVR-HA constructs encoding H5HA from A/Vietnam/1203/2004 (Vietnam, clade 1), A/Indonesia/5/ 2005 (Indonesia, subclade 2.1.3.2), A/Turkey/65596/2006 (Turkey, subclade 2.2.1), A/common magpie/Hong Kong/5052/ 2007 (HK5052, subclade 2.3.2.1), A/Shenzhen/406H/2006 (Shenzhen, subclade 2.3.4), A/Shanxi/2/2006 (Shanxi, clade 7), and pCMVR-N1NA construct encoding NA from A/Thailand/ (KAN-1)/2004 were used to prepare H5N1 pseudotypes.

All sera were heat inactivated and analysed in duplicate (4fold serial dilution, starting from 1:10) with H5N1 pseudotypes corresponding to 20,000 to 200,000 relative luciferase activity (RLA), as previously described (20). The pseudotype-based neutralization $(\mathrm{PN})$ titer $\left(\mathrm{IC}_{80}\right)$ was determined as the reciprocal of the sera dilution giving $80 \%$ reduction of RLA. PN titers were normalized based on HIV-1 gag p24 quantities for different pseudotypes. Non-detected samples were assigned a value of 2 for calculation purpose.

\section{Enzyme-Linked Immunosorbent Assay}

H5HA stalk and N1NA specific immunoglobulin G (IgG) were quantified in sera using the enzyme-linked immunosorbent assay (ELISA) developed in-house, as previously described (21). Serially diluted sera were analysed in Maxi Sorp 96-well plates coated with $1 \mu \mathrm{g} / \mathrm{ml}$ recombinant chimeric HA (cH9/5HA) that combines the H5HA stalk domain from NIBRG-14 strain with an HA globular head domain from A/guinea fowl/Hong Kong/ WF10/1999 H9 influenza A virus, or $1 \mu \mathrm{g} / \mathrm{ml}$ recombinant $\mathrm{N} 1$ neuraminidase. Immunoglobulin concentrations were interpolated from standard human IgG curves. For calculation purposes, non-detected samples were assigned as $0.04 \mu \mathrm{g} / \mathrm{ml}$ against $\mathrm{cH} 9 / 5 \mathrm{HA}$ and $0.005 \mu \mathrm{g} / \mathrm{ml}$ against N1NA.

\section{Virus Neutralization Assay}

All sera were heat inactivated and analysed in duplicate (2-fold serial dilution, starting from 1:10) with $100 \mathrm{TCID}_{50}$ reassortant cH9/1N3 virus in MDCK cells, as previously described (22). The cH9/1N3 virus contains the HA stalk domain from A/California/ 07/2009 H1 strain, an HA globular head domain from A/guinea fowl/Hong Kong/WF10/1999 H9 strain, and N3NA from A/ swine/Missouri/4296424/2006 virus. The virus neutralization (VN) titer was measured with $0.7 \%$ turkey red blood cells and determined as the highest serum dilution giving complete hemagglutination. Non-detected samples were assigned a value of 5 for calculation purpose.

\section{Enzyme-Linked Lectin Assay}

All sera were treated at $56^{\circ} \mathrm{C}$ for $45 \mathrm{~min}$ and analysed in duplicate (3-fold serial dilution, starting from 1:5) with a reassortant NIBRG-73 virus, as previously described (22). The NIBRG-73 virus has N1NA from the NIBRG-14 strain and H7HA from A/ equine/Prague/1956 virus. The neuraminidase enzymatic activity was measured with fetuin, horseradish peroxidase-conjugated peanut agglutinin and o-phenylenediamine dihydrochloride (Sigma-Aldrich), and read as optical density (OD) value at $490 \mathrm{~nm}$. The neuraminidase inhibition $(\mathrm{NI})$ titer $\left(\mathrm{IC}_{50}\right)$ was calculated as the reciprocal dilution of sera giving $50 \%$ reduction in enzymatic activity. Non-detected samples were assigned a value of 2 for calculation purpose.

\section{Antibody-Dependent Cellular Cytotoxicity Reporter Assay}

All sera were heat inactivated, serially diluted and analysed using ADCC Reporter Bioassay kit (Promega), as previously described (22). MDCK cells infected with NIBRG-14 virus at multiplicities of infection (MOI) 0.34 were used as target cells, and Jurkat/ NFAT-luc cells were used as effect cells. The antibody-dependent cellular cytotoxicity (ADCC) reporter activity was measured with Bio-Glo Luciferase Assay Reagent (Promega) as relative luciferase activity (RLA). ADCC titer $\left(\mathrm{EC}_{50}\right)$ was calculated as the reciprocal dilution of sera giving $50 \%$ of maximum RLA. Non-detected samples were assigned a value of 2 for calculation purpose.

\section{Passive Transfer and Viral Challenge in Mice}

Six to eight weeks old female BALB/c mice (Taconic, Denmark) were housed under specific-pathogen free conditions at Rikshospitalet, Oslo University Hospital. All animal experiments were approved by the Norwegian Food Safety Authority.

Pooled human sera or saline $(400 \mu \mathrm{l} /$ mouse) were injected intraperitoneally (i.p.) into mice ( $n=12 /$ group) 1 day prior to viral challenge. Mice were anaesthetized by subcutaneous (s.c.) injection of Hypnorm/Dormicum $(0.05 \mathrm{ml}$ working solution/ $10 \mathrm{~g})$ and infected intranasally (i.n.) with $5 \mathrm{MLD}_{50}$ of NIBRG-14 virus in $20 \mu \mathrm{l} /$ mouse $(10 \mu \mathrm{l} /$ nostril). Mice were monitored for survival and weight loss for 2 weeks after challenge, with an endpoint of $20 \%$ weight reduction, as required by the Norwegian Food Safety Authority. Mice that lost more than $20 \%$ body weight were euthanized by cervical dislocation. For mice that did not lose weight during the 2-week monitoring, the maximum body weight loss was assigned as $0.01 \%$ for calculation purpose. At days 3 and 5 post challenge, both lobes of lungs were harvested ( $\mathrm{n}=3 \mathrm{mice} /$ group), snap frozen and stored at $-80^{\circ} \mathrm{C}$ until use.

\section{Virus Quantification}

Frozen lung tissues were weighted and homogenized in DMEM with $1 \%$ antibiotics. NIBRG-14 virus was quantified in $\mathrm{TCID}_{50}$ on MDCK cells (23). Hemagglutination assay with $0.7 \%$ human red blood cells was used to measure the viral load. The limit of detection was $22.49 \mathrm{TCID}_{50} / \mathrm{ml}$ of homogenate. 


\section{Phylogenetic Tree}

Full-length HA protein amino acid sequences from influenza type A viruses were downloaded from NCBI Influenza Virus Database. Phylogenetic analyses were performed at ngPhylogeny.fr using MAFFT (Multiple Alignment using Fast Fourier Transform, default settings), BMGE (Block Mapping and Gathering with Entropy, default settings), and PhyML (Phylogeny software based on the Maximum-likelihood, default settings) $(24,25)$. See Supplementary Table 1 for the accession no. of all HA amino acid sequences used.

\section{Statistical Analyses}

Biological replicates were used in all experiments, unless otherwise stated. Antibody quantification results including HI, PN, VN, NI, ADCC titers, and IgG concentrations, and lung viral load results were Ln transformed prior to statistical tests. Turkey's multiple comparisons and Fisher's LSD test were performed in two-way analysis of variance (ANOVA). False Discovery Rate controlled multiple comparisons were performed in Nonparametric KruskalWallis test. Nonparametric Spearman correlations and Pearson correlations were tested, linear fitting curves were plotted when Spearman or Pearson $\mathrm{P}<0.10$. In multiple linear regression analyses, all independent variables were centered prior to test. * $\mathrm{P}<0.05,{ }^{* *} \mathrm{P}<0.01,{ }^{* *} \mathrm{P}<0.001$, all $\mathrm{P}$ values are two-tailed. All statistical analyses were performed with GraphPad Prism 7 and SPSS 25.

\section{RESULTS}

\section{Study Design}

Sixty adults were divided into 4 groups and vaccinated with the $\mathrm{H} 5 \mathrm{~N} 1$ virosomal vaccine alone or escalating doses of adjuvanted

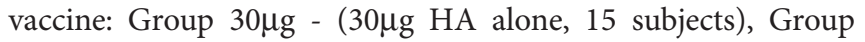
$1.5 \mu \mathrm{g}+(1.5 \mu \mathrm{g}$ HA with adjuvant Matrix M, 15 subjects), Group $7.5 \mu \mathrm{g}+(7.5 \mu \mathrm{g}$ HA with adjuvant Matrix M, 15 subjects $)$, and Group $30 \mu \mathrm{g}+(30 \mu \mathrm{g}$ HA with adjuvant Matrix M, 15 subjects $)$. All subjects received a boosting dose 3 weeks after the first priming dose, except for one withdrawal after the first dose in $7.5 \mu \mathrm{g}+$ group (Figure 1A). Twenty-five subjects had earlier received seasonal influenza vaccine(s) or reported influenza virus infection (Table 1). Sequential pre- and post-vaccination serum samples up to 42 days were collected from all vaccinees.

\section{Adjuvanted H5N1 Vaccines Rapidly Elicits Strain Specific and Broadly Cross-Clades Neutralizing Antibodies}

We assessed HA specific antibodies using the HI assay. None of the vaccinees had detectable antibodies before vaccination. After priming, only the $30 \mu \mathrm{g}+$ group showed potent increases of vaccine specific antibodies. After boosting, all 3 adjuvanted groups had antibodies above the protective level (HI titer $\geq 32$ ), while the non-adjuvanted $30 \mu \mathrm{g}$ - group remained below the protective level (Figure 1B). The $1.5 \mu \mathrm{g}+$ group had significantly lower antibody fold-induction after priming compared to the $30 \mu \mathrm{g}+$ group, while after boosting the difference diminished.
On the contrary, the $30 \mu \mathrm{g}$ - group showed significant antibody induction after priming but limited further increase after boosting (Figure 1C).

We further analysed antibody responses using pseudotypebased neutralization (PN) assay. In 24 subjects, low levels of preexisting vaccine specific neutralizing antibodies were detected. Of note, the vaccine elicited potent homologous antibody responses 7 days after priming in all 4 groups, which were further significantly elevated to higher level in the $1.5 \mu \mathrm{g}+$ and $7.5 \mu \mathrm{g}+$ groups after boosting. The $1.5 \mu \mathrm{g}+$ group had lower antibody fold-induction after priming compared to the $30 \mu \mathrm{g}+$ group but reached similar neutralizing antibody titer after boosting; whilst the $30 \mu \mathrm{g}$ - group had rapid antibody increase 7 days after priming but no significant boost after the second dose (Figures 1E, F).

To explore the breadth of the vaccine elicited crossneutralizing antibodies, we developed a panel of $\mathrm{H} 5 \mathrm{~N} 1$ pseudotypes expressing divergent $\mathrm{H} 5$ hemagglutinins covering multiple (sub)clades of $\mathrm{H} 5 \mathrm{~N} 1$ viruses isolated from humans (Figure 1D and Supplementary Table 1). Remarkably, crossneutralizing antibodies were elicited to equivalent titers as compared to vaccine specific antibodies in all 4 groups when tested against the 3 closely related pseudotypes, namely HK5052 (subclade 2.3.2.1), Turkey (subclade 2.2.1) and Shenzhen (subclade 2.3.4). Meanwhile, although significantly boosted by vaccination, lower levels of cross-neutralizing antibodies were detected to the 2 more distant pseudotypes: Indonesia (subclade 2.1.3.2) and Shanxi (clade 7). Nevertheless, broadly neutralizing antibodies were detected in all the subjects in the $30 \mu \mathrm{g}+$ group across all the (sub)clades (Figure 1G).

\section{Multifaceted Antibody Responses After H5N1 Vaccines}

Total HA stalk specific antibodies were measured in ELISA against the recombinant chimeric protein $\mathrm{cH} 9 / 5 \mathrm{HA}$, which consists of the HA stalk domain from the vaccine strain and an irrelevant H9HA head. All subjects were found to have preexisting HA stalk specific antibodies. As early as 7 days after priming, we observed significant antibody increases in all 4 groups. The $30 \mu \mathrm{g}+$ group had significantly higher antibody fold-induction as compared to the $1.5 \mu \mathrm{g}+$ and $30 \mu \mathrm{g}$ - groups (Figures 2A, B).

We next assessed neuraminidase (NA) specific antibodies by ELISA (Figures 2C, D). In 51 subjects, NA specific antibodies were detected prior to vaccination. The $\mathrm{H} 5 \mathrm{~N} 1$ vaccines elicited potent antibody increases in all 4 groups at 7 days after priming. Further significant antibody increases were found after boosting in $1.5 \mu \mathrm{g}+$ and $7.5 \mu \mathrm{g}+\mathrm{H} 5 \mathrm{~N} 1$ groups (Figure 2C). Overall, the $7.5 \mu \mathrm{g}+$ and $30 \mu \mathrm{g}+$ groups showed equivalently potent responses, while the $1.5 \mu \mathrm{g}+$ and $30 \mu \mathrm{g}$ - groups had lower fold change of NA specific antibodies (Figure 2D).

To quantify the antibodies that inhibit NA enzymatic activity, we performed enzyme-linked lectin assay (ELLA). Before vaccination, detectable NA inhibition (NI) titers were observed in 36 of 60 subjects. Vaccinees in the groups $30 \mu \mathrm{g}-, 7.5 \mu \mathrm{g}+$ and $30 \mu \mathrm{g}+$ had significant antibody increases 7 days after priming. While vaccinees in the $1.5 \mu \mathrm{g}+$ group showed antibody induction 


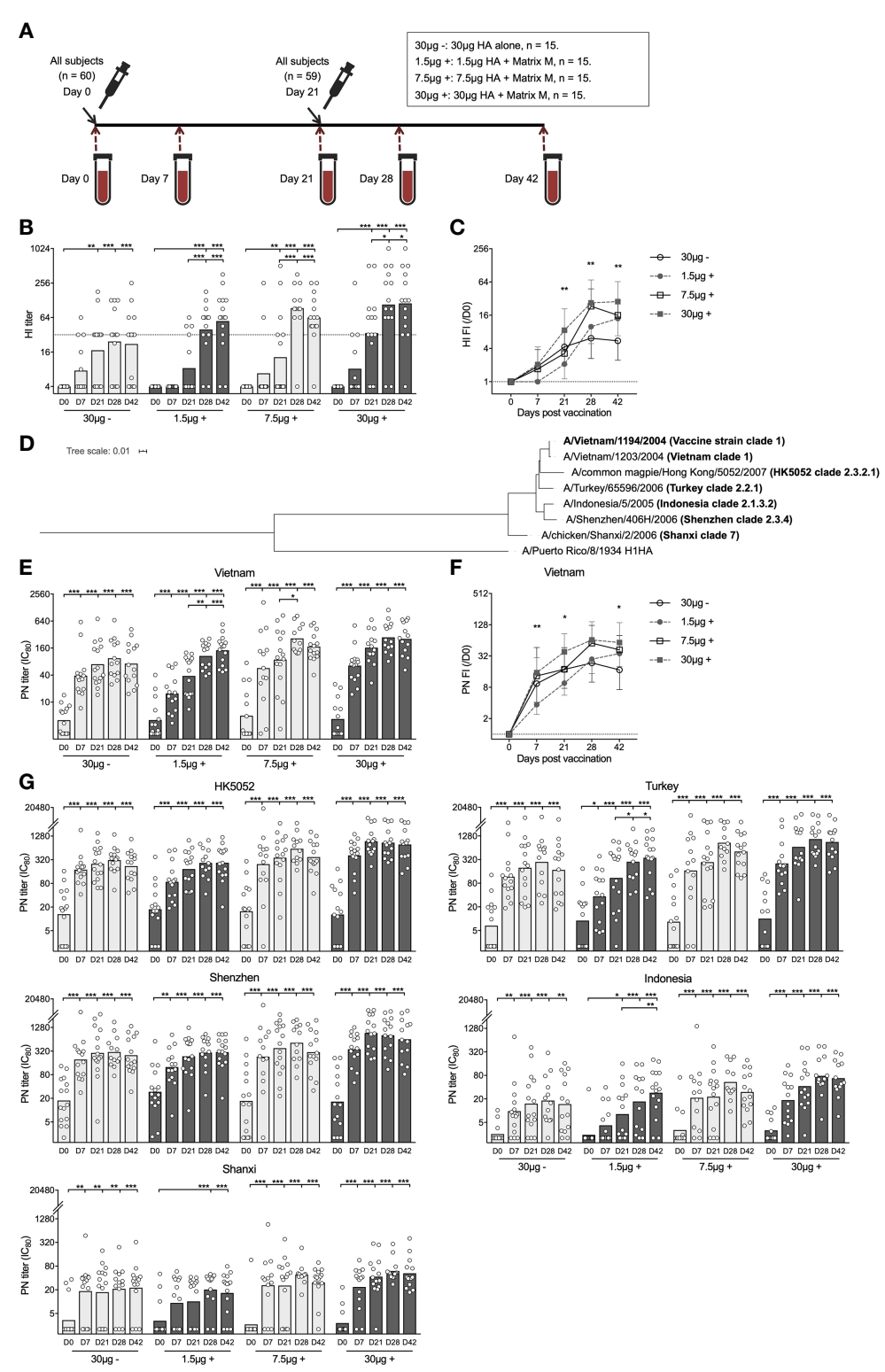

FIGURE 1 | Adjuvanted H5N1 vaccine rapidly elicited strain specific and cross-reactive neutralizing antibody responses. (A) An lllustration of the study design. Sixty adults (20 to 49 years old) were enrolled in this study and vaccinated with inactivated virosomal H5N1 vaccine (Crucell| Berna Biotech, Switzerland). The adults were randomized into 4 groups of 15 subjects and received two doses of H5N1 vaccine with $30 \mu \mathrm{g}$ hemagglutinin (HA) alone (30 $\mu \mathrm{g}-)$, or 1.5, 7.5 and $30 \mu \mathrm{g} \mathrm{HA}$ adjuvanted with Matrix $\mathrm{M}(1.5 \mu \mathrm{g}+, 7.5 \mu \mathrm{g}+$, and $30 \mu \mathrm{g}+$, respectively), at an interval of 21 days. Serum samples pre- (day 0$), 7$ days, 21 days, 28 days, and 42 days post-vaccination were collected. One subject withdrew after first dose vaccine in $7.5 \mu \mathrm{g}+$ group. (B, C) Hemagglutination inhibiting titer (HI titer, B) and foldinduction (FI) after vaccination ( $\mathrm{HI} \mathrm{FI,/DO,} \mathrm{C)} \mathrm{was} \mathrm{measured} \mathrm{against} \mathrm{NIBRG-14} \mathrm{virus} \mathrm{(vaccine} \mathrm{strain).} \mathrm{(D)} \mathrm{Phylogenetic} \mathrm{tree} \mathrm{shows} \mathrm{the} \mathrm{genetic} \mathrm{divergence} \mathrm{between}$ $\mathrm{H} 5 \mathrm{HA}$ from the vaccine strain and heterologous H5HAs tested in pseudotype-based neutralization (PN) assay. H1HA from A/Puerto Rico/8/1934 was used as a reference. Phylogenetic analyses were performed at ngPhylogeny.fr. (E, F) Vaccine specific neutralizing antibodies were measured in PN assay against pseudotyped virus derived from AVietnam/1203/2004 virus (Vietnam). The PN titer ( $\left(\mathrm{C}_{80}\right.$, E) was calculated as the reciprocal dilutions of the sera that gave 80\% inhibition. Foldinduction after vaccination $(\mathrm{PN} \mathrm{Fl}, / \mathrm{DO}, \mathbf{F})$ is shown. (G) Cross-neutralizing antibody titers $\left(\mathrm{I}_{80}\right)$ were measured against 5 strains of pseudotypes expressing heterologous H5HAs listed in D All antibody responses were measured using serum samples before (D0) and after vaccination (D7, D21, D28, and D42). The geometric mean values are shown as bars, and each symbol represents one subject (B, E, G). The geometric mean of fold-inductions in each group \pm geometric standard deviation as error bar is shown (C, F). ${ }^{*} \mathrm{P}<0.05,{ }^{\star \star} \mathrm{P}<0.01,{ }^{* \star *} \mathrm{P}<0.001$ (Antibody titers and fold-inductions were $\mathrm{Ln}$ transformed in statistical analyses. Turkey's multiple comparisons between pre-prime (D0) and post-prime (D7, D21, D28, D42), and between pre-boost (D21) and post-boost (D28 and D42) in each group were performed in two-way ANOVA in (B, E, G) Turkey's multiple comparisons between $30 \mu \mathrm{g}+$ and $1.5 \mu \mathrm{g}+$ after prime (D7 and D21), and between $30 \mu \mathrm{g}+$ and $30 \mu \mathrm{g}$ - after boost (D28 and D42) were performed in two-way ANOVA in C, F). The horizontal dotted lines indicate HI titer of 32 (B), and fold-induction of 1 (C, F). Duplicates were performed in all experiments. 
TABLE 1 | The demographics of the subjects enrolled in the study.

\begin{tabular}{|c|c|c|c|c|c|}
\hline $\begin{array}{l}\text { Group } \\
\left.\text { (Vaccine administered }^{1}\right)\end{array}$ & $\begin{array}{l}\text { Total } \\
\left(\mathrm{N} / \mathrm{A}^{2}\right)\end{array}$ & $\begin{array}{c}30 \mu \mathrm{g}- \\
(30 \mu \mathrm{g} \mathrm{HA})\end{array}$ & $\begin{array}{c}1.5 \mu \mathrm{g}+(1.5 \mu \mathrm{g} \text { HA adjuvanted } \\
\text { with } 50 \mu \mathrm{g} \text { Matrix M) }\end{array}$ & $\begin{array}{c}7.5 \mu \mathrm{g}+(7.5 \mu \mathrm{g} \text { HA adjuvanted } \\
\text { with } 50 \mu \mathrm{g} \text { Matrix M) }\end{array}$ & $\begin{array}{c}30 \mu \mathrm{g}+(30 \mu \mathrm{g} \text { HA adjuvanted } \\
\text { with } 50 \mu \mathrm{g} \text { Matrix M) }\end{array}$ \\
\hline No. of subjects & 60 & 15 & 15 & $15^{3}$ & 15 \\
\hline Gender, M/F & $22 / 38$ & $6 / 9$ & $5 / 10$ & $7 / 8$ & $4 / 11$ \\
\hline Median age, years & 30 & 30 & 26 & 28 & 30 \\
\hline (Range) & $(20-49)$ & $(20-41)$ & $(21-44)$ & $(22-42)$ & $(25-49)$ \\
\hline $\begin{array}{l}\text { No. of subjects with previous } \\
\text { vaccinations and/or infection }{ }^{4}\end{array}$ & 25 & 6 & 8 & 4 & 7 \\
\hline
\end{tabular}

21 days after priming, which increased significantly after boosting (Figure 2E). The kinetics of NI antibody fold change among 4 vaccine groups was similar to the kinetics of NA specific binding antibodies by ELISA (Figures 2D, F).

Lastly, we measured ADCC inducing antibodies. Thirty-seven out of 60 subjects had pre-existing ADCC inducing antibodies. The $\mathrm{H} 5 \mathrm{~N} 1$ vaccines further elevated the antibody levels, which remained high after boosting in all groups, especially the $30 \mu \mathrm{g}+$ group (Figures 2G, H).

In summary, the virosomal $\mathrm{H} 5 \mathrm{~N} 1$ vaccines elicited potent and multifaceted antibody responses. The adjuvanted intermediate $(7.5 \mu \mathrm{g}+)$ and high $(30 \mu \mathrm{g}+)$ dose vaccines potently induced antibody increases 7 days after priming, which were further elevated or maintained after boosting. By comparison, the adjuvanted low $(1.5 \mu \mathrm{g}+)$ dose vaccine showed delayed

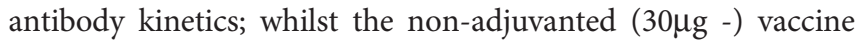
elicited antibodies of an overall lower magnitude.

\section{H5N1 Vaccines Induced Robust Antibody Responses}

As the majority of our subjects had some detectable antibodies against the $\mathrm{H} 5 \mathrm{~N} 1$ vaccine components prior to vaccination, we investigated whether pre-existing immunity hampers the $\mathrm{H} 5 \mathrm{~N} 1$ vaccine elicited antibody responses. Firstly, the age of the subjects enrolled in this study ranged from 20 to 49 years old (Table 1). We saw significant correlations between the age and pre-existing level of neutralizing antibodies, HA stalk and NA specific binding antibodies (Figure 3A). In contrast, the antibody levels after $\mathrm{H} 5 \mathrm{~N} 1$ vaccination had inverse or no correlation with age (Figure 3B). Next, subjects who had had seasonal influenza vaccination or infection within 5 years prior to the current study showed significantly higher levels of pre-existing neutralizing, NA specific and ADCC inducing antibodies. H5N1 vaccination boosted antibodies to comparably high levels in all subjects (Figure 3C). Collectively, the $\mathrm{H} 5 \mathrm{~N} 1$ vaccines induced robust and multifaceted antibody responses regardless of age, vaccination/infection history or pre-existing antibody levels.

\section{Human Immune Post H5N1 Vaccination Sera Confer In Vivo Protection}

To study whether the $\mathrm{H} 5 \mathrm{~N} 1$ vaccine induced antibodies are protective against infection, we performed passive serum transfer and virus challenge in a murine model. Briefly, we pooled prevaccination sera from groups $1.5 \mu \mathrm{g}+$ and $30 \mu \mathrm{g}+$ as D0 sera, and post-vaccination sera were pooled within each group from all vaccinees in the $1.5 \mu \mathrm{g}+$ and $30 \mu \mathrm{g}+$ groups for days 7,21 and 42. Pooled immune sera or saline were then transferred into mice one day prior to a viral challenge $\left(5 \times \mathrm{MLD}_{50}\right)$ with the NIBRG-14 virus. Body weight was monitored for 14 days after challenge (Figure 4A). Mice that received saline or D0 sera became ill and rapidly lost weight. All 5 mice receiving saline and 2 out of 6 mice receiving D0 sera died between days 7 and 8 after challenge. By contrast, all mice that received post-vaccination sera survived. Mice that received sera 7 and 21 days post-vaccination from group $1.5 \mu \mathrm{g}$ + showed mild symptoms and lost a maximum of $16 \%$ and $9.3 \%$ of body weight, respectively, although they quickly recovered. Mice receiving day 42 sera from the group $1.5 \mu \mathrm{g}+$ and sera at all 3 time points from the group $30 \mu \mathrm{g}+$ displayed no symptoms of disease and had $<3 \%$ body weight loss at maximum (Figures 4B-D).

We measured the lung weight and viral load at 3 and 5 days after challenge. Mice that received days 21 and 42 sera from group $30 \mu \mathrm{g}+$ showed lower lung weight at 5 days post challenge, and lower viral loads at days 3 and 5, compared to the mice receiving saline (Figures 4E, F). In addition, we observed good correlations between the lung viral load and body weight loss, as well as between the lung viral load and the lung weight (Figures 4G, H). To summarise, immune sera elicited by $\mathrm{H} 5 \mathrm{~N} 1$ vaccination, especially the adjuvanted high dose $(30 \mu \mathrm{g}+)$, conferred full protection against a lethal in vivo challenge.

\section{Neutralizing Antibody and Neuraminidase Inhibiting Antibody Titers Act as Correlates of Protection}

Our final aim was to study which of the $\mathrm{H} 5 \mathrm{~N} 1$ vaccine elicited antibody responses correlated with in vivo protection. We included the widely used hemagglutination inhibition (HI) titer, neutralizing antibody titer measured in pseudotype-based assay (PN titer), hemagglutinin stalk specific antibody level (HA stalk IgG) and neuraminidase inhibition (NI) titer as candidates for correlates of protection. As the $\mathrm{Fc}$ receptors involved in ADCC are different between humans and mice, the ADCC inducing antibody titer was not included in analyses.

Importantly, we observed inverse correlations between the antibody levels in the pooled human sera that mice received by 
A

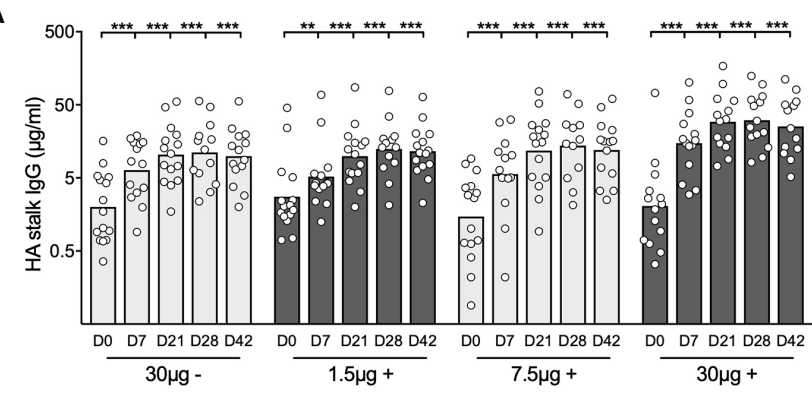

C

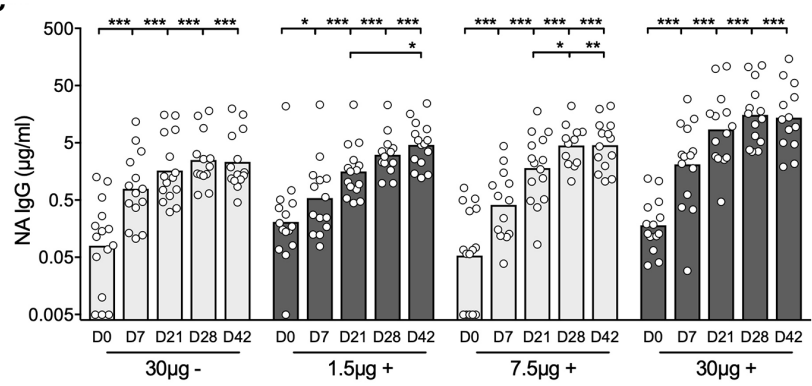

E

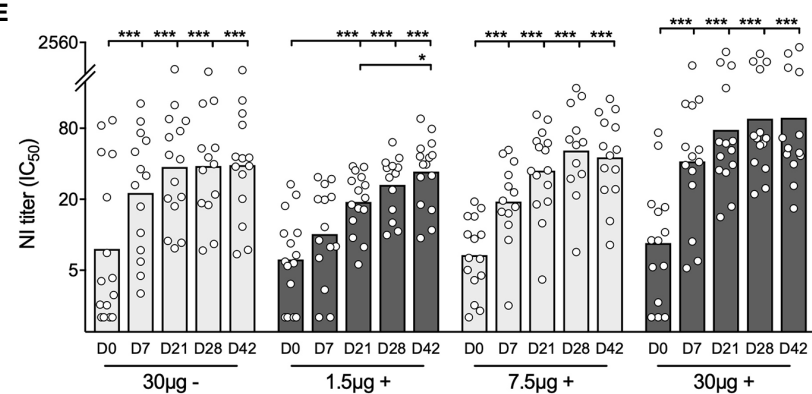

G

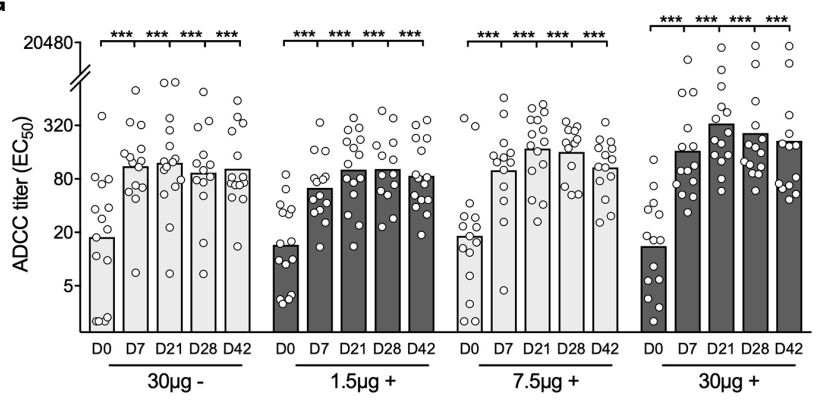

B

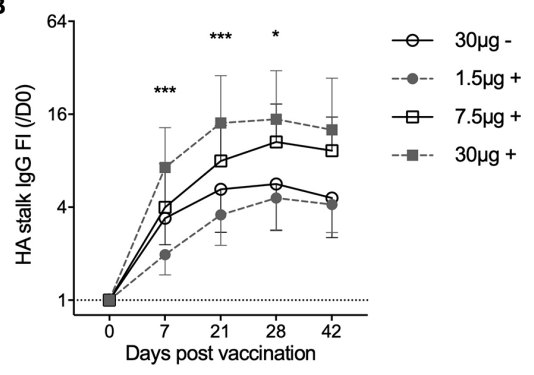

D

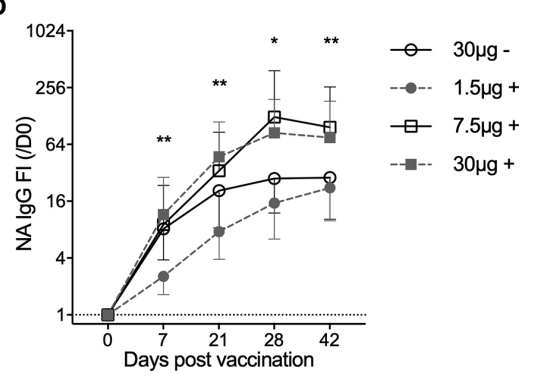

$\mathbf{F}$

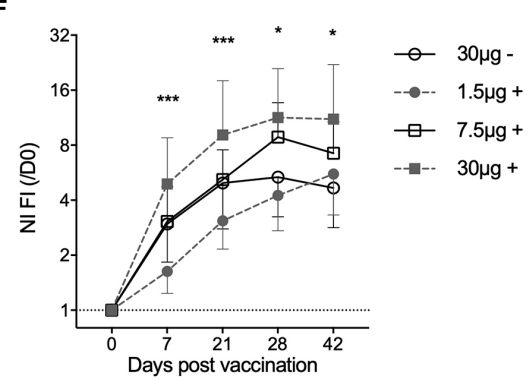

H

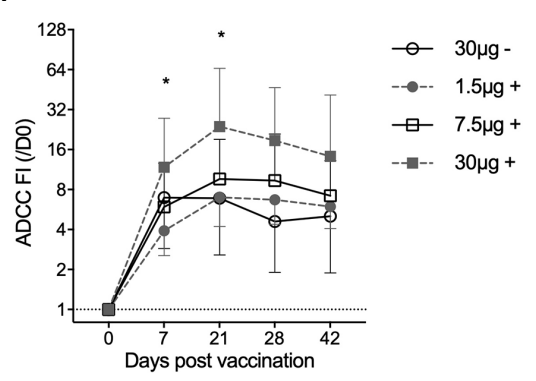

FIGURE 2 | Adjuvanted H5N1 vaccines elicit multifaceted antibody responses. (A, B) H5HA stalk specific antibodies were measured against the recombinant chimeric protein $\mathrm{CH} 9 / 5 \mathrm{HA}$, which consists of $\mathrm{HA}$ stalk domain from $\mathrm{H} 5$ AVietnam/1203/2004 strain and irrelevant $\mathrm{H} 9 \mathrm{HA}$ head domain. Concentrations of total $\mathrm{H} 5 \mathrm{HA}$ stalk specific antibody measured in ELISA (A) and fold-induction (Fl) after vaccination (IgG Fl,/DO, B) are shown. (C, D) Total neuraminidase (NA) specific antibodies were measured in ELISA against N1NA from AVietnam/1203/2004 virus. Antibody concentrations (C) and fold-induction after vaccination (lgG FI,/D0, D) are shown. (E, F) Pre- and post-vaccination sera were tested for inhibiting NA enzymatic activity in ELLA against reassortant NIBRG-73 virus, which expresses NA from H5N1 vaccine strain and irrelevant $\mathrm{H} 7 \mathrm{HA}$. The neuraminidase enzymatic activity inhibition titer ( $\mathrm{NI} I \mathrm{C} 50$, E) was calculated as the reciprocal dilutions of the sera that gave $50 \%$ inhibition. Fold-induction after vaccination (NI FI,/DO, F) is shown. (G, H) Sera were tested for inducing antibody-dependent cellular cytotoxicity (ADCC) in ADCC Reporter Bioassay against the vaccine strain (NIBRG-14). The ADCC titer (EC50, G) was calculated as the reciprocal dilutions of the sera that gave 50\% of the maximal biological response. Fold-induction after vaccination (ADCC Fl,/DO, $\mathbf{H}$ ) is shown. The geometric mean titers are shown as bars, and each symbol represents one subject (A, C, E, G). The geometric means of fold-induction in each group \pm geometric standard deviation as error bar are shown $\mathbf{( B ,} \mathbf{D}, \mathbf{F}, \mathbf{H})$. ${ }^{\star} \mathrm{P}<0.05,{ }^{\star \star} \mathrm{P}<$ $0.01,{ }^{\star \star \star} \mathrm{P}<0.001$ (Antibody titers and fold-inductions were Ln transformed in statistical analyses. Turkey's multiple comparisons between pre-prime (D0) and postprime (D7, D21, D28, D42), and between pre-boost (D21) and post-boost (D28 and D42) in each group were performed in two-way ANOVA in A, C, E, G. Turkey's multiple comparisons between $30 \mu \mathrm{g}+$ and $1.5 \mu \mathrm{g}+$ after prime (D7 and D21), and between $30 \mu \mathrm{g}+$ and $30 \mu \mathrm{g}-$ after boost (D28 and D42) were performed in two-way ANOVA in B, D, F, H). The horizontal dotted lines indicate fold-induction of 1 (B, D, F, H). Duplicates were performed in all experiments. 

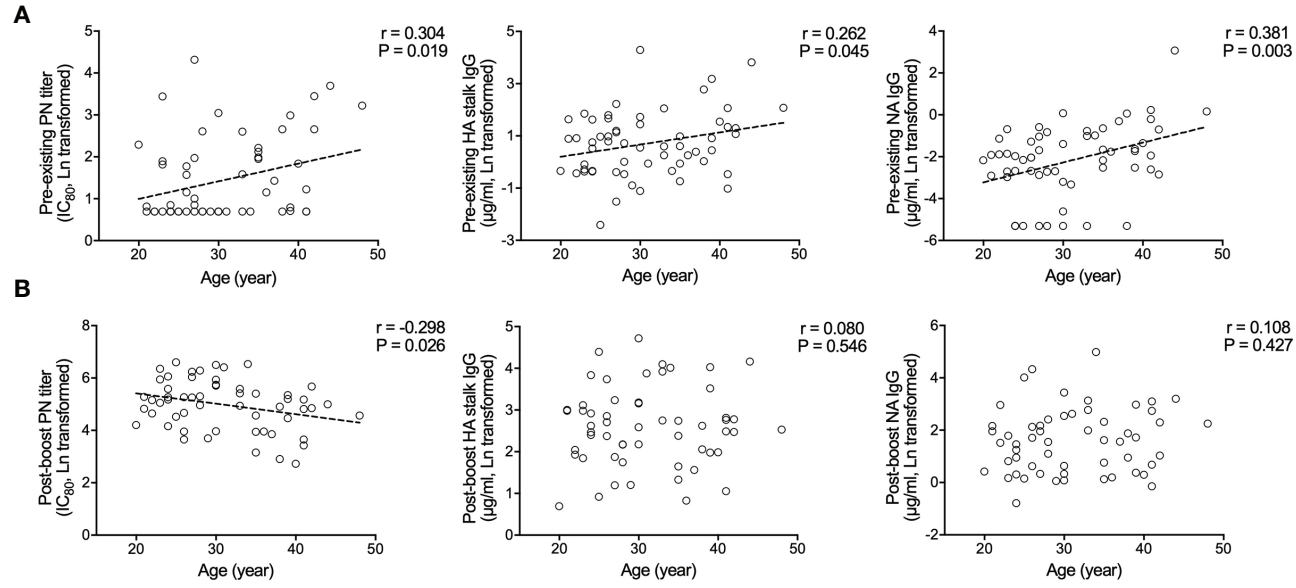

C
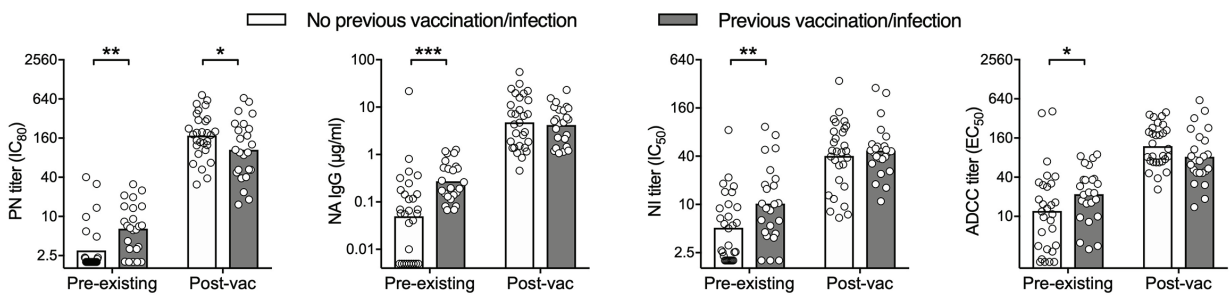

FIGURE 3 | H5N1 vaccines elicit potent antibody responses regardless of pre-existing humoral immunity. (A, B) HA specific neutralizing antibodies (PN titer, left), total HA stalk specific antibodies (IgG, center) and total NA specific antibodies (IgG, right) tested in pre-vaccination sera (pre-existing, D0, A) correlate with age. Inverse or no significant correlation with age is found in sera after vaccination (post-vac, D42, B). (C) Subjects with previous vaccination and/or infection had significantly higher pre-existing antibodies, compared to subjects without previous vaccination or infection. After vaccination, the difference was abolished. $\mathrm{HA}$ specific neutralizing antibodies (PN titer, far left), total NA specific antibodies (lgG, central left), neuraminidase enzymatic activity inhibiting antibodies (NI titer, central right), and antibody-dependent cell-mediated cytotoxicity (ADCC) inducing antibodies (ADCC titer, far right) were tested in sera before (pre-existing) and 42 days after vaccination (post-vac). The geometric mean titers are shown as bars (C), and each symbol represents one subject (A-C). Linear fitting curve was plotted as dotted line when Pearson correlation $\mathrm{P}<0,05$. Pearson $r$ and $\mathrm{P}$ values are noted for each correlation (A, B). ${ }^{*} P<0.05,{ }^{* \star} P<0.01,{ }^{* \star *} P<0.001$ (Antibody titers and concentrations were Ln transformed in statistical analyses. Fisher's LSD test between subjects with previous vaccination/infection and subjects without was performed in two-way ANOVA in (C).

passive transfer and murine body weight loss, as well as lung viral load after challenge (Figures 5A, B). Of note, the NI titer had the closest relationship with both murine body weight loss and lung viral load, followed by PN titer. Whilst the HI titer and HA stalk IgG level showed lower degrees of correlation with in vivo protection, determined by the Peason's $r$ values in correlation analyses.

We further dissected the contribution of each antibody parameter to the predictions of in vivo protection. The adjusted $\mathrm{R}$ square and the standard error of the estimate in the multiple linear regression analyses were used to determine the level of fit in different prediction models. When predicting the maximum body weight loss, PN titer and NI titer alone or combined were among the best-fit models (Figure 5C and Supplementary Table 2). In the lung viral load predictions, NI titer alone, NI and PN titer combined, and all 4 antibody parameters together were the top 3 models (Figure 5D and Supplementary Table 2). Notably, NI titer contributed significantly to the top models predicting both body weight loss and lung viral load (Figures 5C, D and Supplementary Table 3). Together, our correlation and regression analyses on the in vivo protection provided by pooled human sera in murine challenge model cohesively demonstrated that PN and NI titers act as correlates of protection. Further study is needed to confirm the roles of PN and NI titers as correlates of protection in human infection scenario.

\section{DISCUSSION}

Since 1996, highly pathogenic avian influenza (HPAI) H5N1 have caused outbreaks in domestic and wild birds worldwide, as well as sporadic zoonotic-human transmissions $(3,26)$. The high mortality rate in confirmed human infections raised alarms about the global pandemic preparedness (1). Dozens of pre-pandemic H5N1 candidates have been developed, and clinical trials have been conducted with vaccines developed in various platforms $(3,5)$. Here, we investigated in-depth the multifaceted antibody responses after a virosomal $\mathrm{H} 5 \mathrm{~N} 1$ vaccine alone or with the Matrix M adjuvant. Our data showed that the adjuvanted H5N1 vaccines elicited potent vaccine-specific and broadly cross-neutralizing antibodies, as well as HA stalk and NA specific functional antibodies. The multifaceted antibody responses were found as early as 7 days after the first dose and were further boosted and 
A

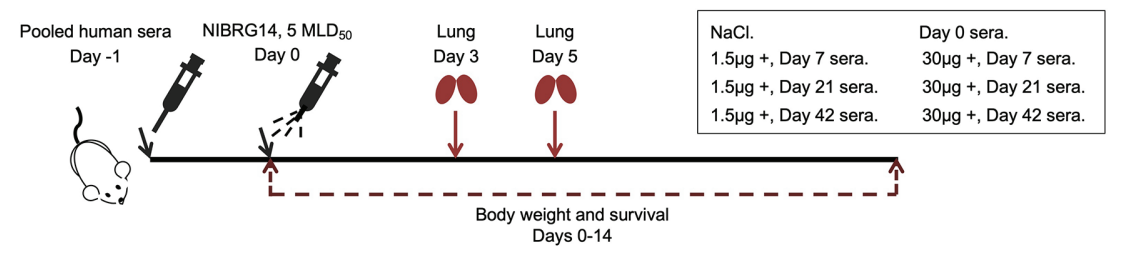

B

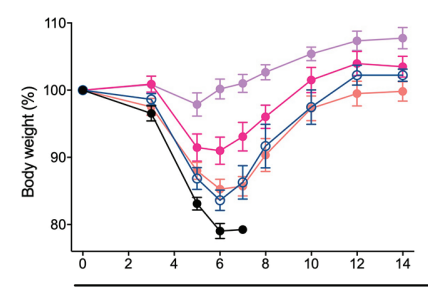

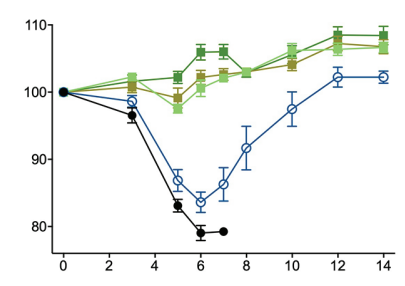

C

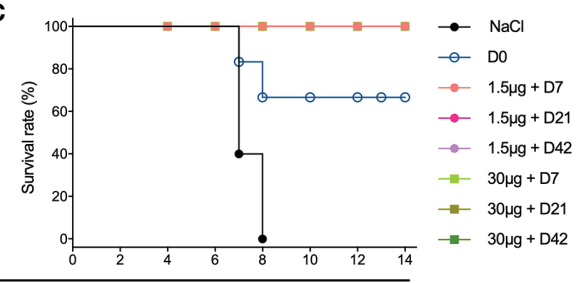

Days post challenge

D

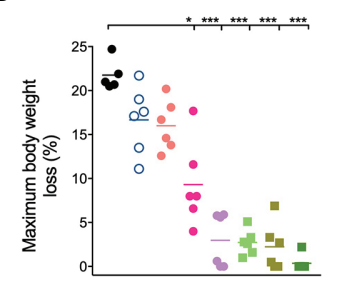

E

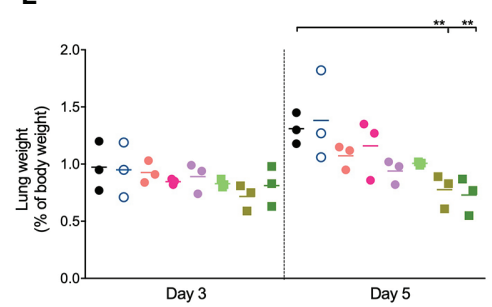

F

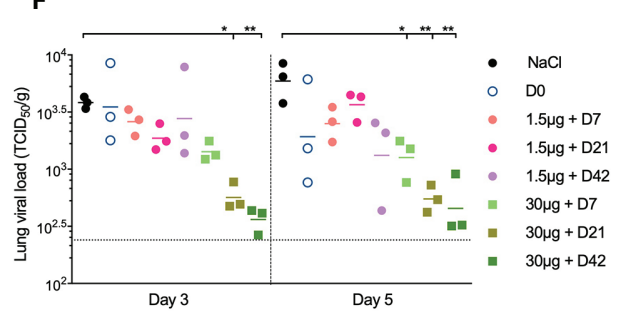

G

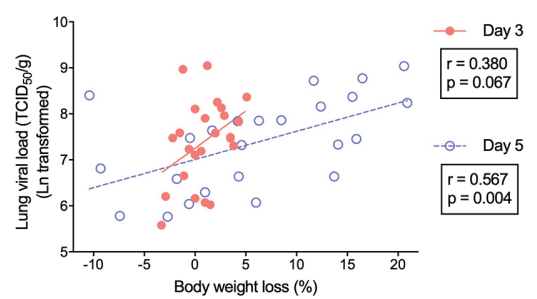

H

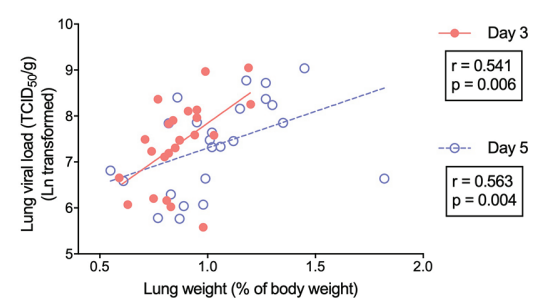

FIGURE 4 | Adjuvanted H5N1 vaccines elicit antibodies provided in vivo protection against lethal virus challenge. (A) Illustration of the experiment set-up for serum transfer and virus challenge. Pre-vaccination sera from subjects in $1.5 \mu \mathrm{g}+$ and $30 \mu \mathrm{g}+$ groups were pooled together as D0 sera. Sera from days 7,21 and 42 after vaccination from subjects in $1.5 \mu \mathrm{g}+$ or $30 \mu \mathrm{g}+$ groups were pooled separately. Group-and time-point-wise pooled sera were administered intraperitoneally to female BALB/c mice ( $n=12$ per group). NaCl was given as control. One day later, the mice were infected intranasally with $5 \times 50 \%$ mice lethal dose (MLD50) of NIBRG-14 virus. Body weight and survival were monitored for 14 days after challenge. Lungs from 3 mice per group were collected 3 and 5 days after infection for weight and viral load measurement. (B, C) The body weight loss (B) and survival rate (C) of the mice in different groups are shown. (D) Maximum body weight loss was calculated for each individual mouse as the maximum body weight loss through 14 days monitoring, which occurred at 5,6 or 7 days after challenge. For mice with no body weight loss observed through monitoring, maximum weight loss was assigned as $0,01 \%$. (E, F) The lung weight of the 3 mice sacrificed on days 3 and 5 after virus challenge was measured and is shown as the mean of percentage of pre-infection body weight (\% of body weight, E). The viral load of NIBRG-14 virus was measured in MDCK cells as the reciprocal dilutions of lung homogenates that gave $50 \%$ tissue culture infection dose (TCID50) and standardized based on the lung weight (TCID50/g, F). The dotted line indicates the lowest detectable viral load in the assay. (G, H) The standardized lung viral load (TCID50/g) 3 and 5 days after infection correlate with the body weight loss $\mathbf{( G )}$ and the lung weight $\mathbf{( H )}$. The body weight of mice in each group is shown as mean \pm standard deviation as error bar (B). Means (D, E) and geometric means (F) are shown as horizontal lines, and each symbol represents one mouse (D-H). ${ }^{\star} P<0.05$, ${ }^{\star \star} P<0.01$, ${ }^{\star \star \star} P<$ 0.001 (lung viral load was Ln transformed in statistical analyses. False Discovery Rate controlled multiple comparisons between mice receiving $\mathrm{NaCl}$ and pooled sera were performed in Nonparametric Kruskal-Wallis test in D-F). The standardized lung viral load was Ln transformed in statistical analyses. Linear fitting curve is plotted as solid line (Day 3) or dotted line (Day 5) when nonparametric Spearman $\mathrm{P}<0.10$. Spearman $r$ and $\mathrm{P}$ values are noted for each correlation (G, H). Duplicates were performed in lung weight and viral load measurement.

maintained at high levels after the second dose. These antibodies provided full protection against $\mathrm{H} 5 \mathrm{~N} 1$ virus challenge in mice. Of note, the levels of neutralizing antibodies and NA inhibiting antibodies could predict in vivo protection against infection and disease progression.
Like other enveloped RNA virus, influenza viruses evolve continuously due to its error-prone replication and large host reservoirs. Newly emerged strains may thus escape existing immunity established from previous infection and vaccination. The HPAI H5N1 viruses have evolved into multiple clades and 

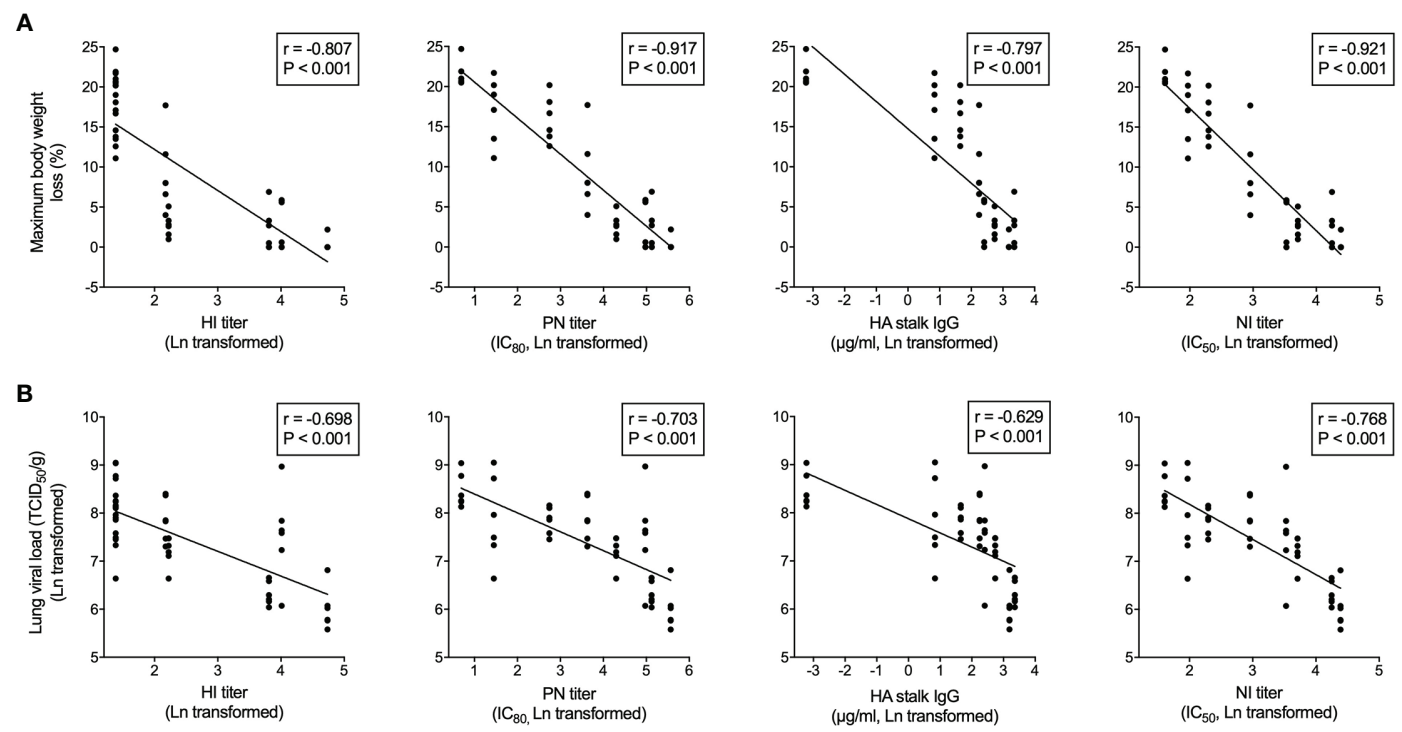

C

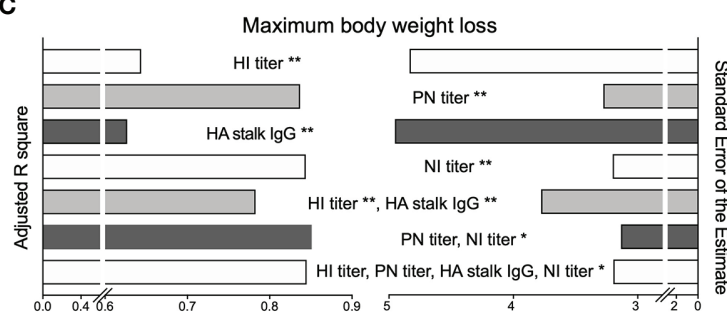

D

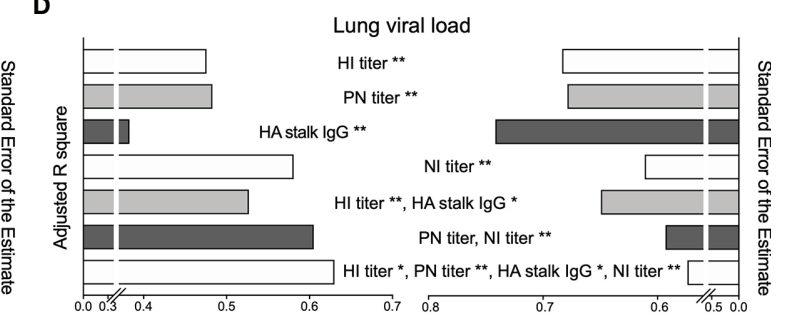

FIGURE 5 | Vaccine elicited HA and NA specific antibodies predict in vivo protection after challenge. (A, B) Hemagglutination inhibition antibodies (HI titer, far left), HA specific neutralizing antibodies (PN titer, central left), total HA stalk specific antibodies (HA stalk lgG, central right), and neuraminidase enzymatic activity inhibiting antibodies (NI titer, far right) significantly and inversely correlate with the maximum body weight loss (A) and lung viral load (B) in mice after NIBRG-14 virus challenge. Each symbol represents one mouse (A, B). The linear fitting curve is plotted as line. Pearson $r$ and $P$ values are noted in each correlation. (C, D) Antibody parameters including $\mathrm{HI}$ titer, PN titer, HA stalk IgG and NI titer results were used to predict mice maximum body weight loss (C) and lung viral load (D) in uni- and multiple linear regression models. Adjusted R square (left half) and Standard Error of the Estimate (right half) are shown to indicate the goodness of different models explaining dependent variables. In each model, predictors contributing significantly are noted. ${ }^{*} \mathrm{P}<0.05,{ }^{* *} \mathrm{P}<0.01$. For detailed model summary and coefficients, see Supplementary Tables 2-3. Antibody parameters from each individual subject in clinical trial were put together in silico the same way as sera were combined to make group-and-time-point-wise pooled human sera for mice passive transfer. Geometric mean of antibody parameter was calculated, Ln transformed and centered before being used as independent variables. Maximum body weight loss and Ln-transformed lung viral load were used as dependent variables in regression analyses in SPSS 25.

subclades. Therefore, vaccines capable of eliciting crossprotective immunity are highly desired. Previous studies on cross-neutralizing antibodies after $\mathrm{H} 5 \mathrm{~N} 1$ vaccines were mostly limited to clades 1 and $2(8,27-30)$. To our knowledge, we are the first to report vaccine-induced cross-neutralizing antibody responses against all $\mathrm{H} 5$ clades found from human infections, including (sub)clades 1, 2.1.3.2, 2.2.1, 2.3.2.1, 2.3.4 and 7. To our surprise, most of the subjects had low to moderate level of antibodies cross-reactive to multiple (sub)clades prior to vaccination. Importantly, the Matrix $M$ adjuvanted virosomal H5N1 vaccine elicited potent neutralizing antibody responses against all 6 (sub)clades, as quickly as 7 days after the first vaccine dose. Similarly, rapid increases in functional non-neutralizing antibodies, such as HA stalk IgG, NA inhibiting and ADCC inducing antibodies, were observed after vaccination (Figures 1, 2). In contrast, our early studies using $\mathrm{HI}$, microneutralization and single radial hemolysis assays showed no measurable preexisting antibodies; and 2 doses of vaccine were required for induction of low to moderate levels of antibodies that could cross neutralize clades 1 and 2 [Supplementary Figure 1 and references (16-18)]. The detection of pre-existing antibodies in this study could be attributed to the higher sensitivity of pseudotype-based neutralization compared to the traditional assays used earlier. The protective potential of these preexisting antibodies has not yet been fully elucidated, but our results from the sera passive transfer and viral challenge in mice indicate that efficient vaccines will still be needed for protection. The different magnitude and kinetics of the antibody response emphasize the necessity of implementing and harmonizing highly sensitive serological assays to fully understand the immune responses. For example, a more balanced distribution of surface glycoproteins and sensitive luminescence readout 
make pseudotype-based neutralization assay more sensitive, quantitative and better suited in detecting zoonotic virus specific antibodies $(19,31,32)$.

Compared to the variable HA head domain, the HA stalk domain and NA are more conserved. Thus, functional antibodies against HA stalk and NA broaden vaccine responses against heterologous strains. Ellebedy et al. reported robust HA stalk antibody responses measured in ELISA after receiving inactivated $\mathrm{H} 5 \mathrm{~N} 1$ vaccine (7). Boudreau C. et al. demonstrated that the MF59-adjuvanted $\mathrm{H} 5 \mathrm{~N} 1$ vaccine elicited antibodies that stimulated robust neutrophil phagocytosis and complement activity (33). In our study, we observed potent increases of HA stalk specific IgGs and ADCC inducing antibodies, which peaked after priming with no further boost after the second vaccine dose. By contrast, cross-neutralizing and NA inhibiting antibodies were significantly elicited after both the priming and boosting dose, especially in the low and intermedium adjuvanted $(1.5 \mu \mathrm{g}+$ and $7.5 \mu \mathrm{g}+)$ groups (Figures 1, 2).

Adjuvants enhance vaccine immunogenicity, especially in the absence of pre-existing immune memory. The Matrix $M$ has been tested in vaccines against malaria and is currently used in the NVXCoV2373 vaccine against COVID-19 (34-38). Here we demonstrated that the Matrix $M$ adjuvanted H5N1 influenza vaccine induced potent increases of broadly cross-neutralizing antibodies, as well as HA stalk and NA specific non-neutralizing antibodies. The adjuvanted $7.5 \mu \mathrm{g}+$ and $30 \mu \mathrm{g}+$ vaccines induced significantly higher titers and better breadth of antibodies as compared to the non-adjuvanted $30 \mu \mathrm{g}$ - group. More importantly, days 21 and 42 post-vaccination sera from $30 \mu \mathrm{g}+$ group provided full protection in mice against both disease progress and viral infection (Figure 4).

The controlled human influenza virus infection model and vaccine field studies are useful in assessing the vaccine effectiveness and establishing correlates of protection $(39,40)$. Unfortunately, it is difficult to conduct such studies with HPAI H5N1 viruses due to the high morbidity and mortality rate associated. We therefore transferred human sera into naïve mice before an in vivo challenge to study relevant correlates of protection. Other studies applying human sera transfer and mice challenge have shown that HA stalk specific antibodies predict in vivo protection against heterologous virus challenge $(41,42)$. Here, our results demonstrated that PN and NI titers had closer correlations with in vivo protection against a homologous virus challenge, as compared to HI titer or HA stalk specific IgG (Figure 5). These results are in agreement with other human challenge (43) and cohort studies (44-46). A caveat here is that our multiple linear regression analyses suffer from inherited collinearity issues due to the similar kinetics of vaccine-elicited antibody responses. Therefore, the coefficients of each predictor may be subject to variance inflation (Supplementary Table 3). Nevertheless, the overall level of predictions should hold accurate (Figures 5C, D and Supplementary Table 2).

In this study, we assessed the kinetics, magnitude and in vivo protection efficacy of the multifaceted antibody responses after the adjuvanted virosomal $\mathrm{H} 5 \mathrm{~N} 1$ vaccines. This vaccine was developed in preparation for a potential $\mathrm{H} 5 \mathrm{~N} 1$ pandemic. Nevertheless, lessons learnt from $\mathrm{H} 5 \mathrm{~N} 1$ vaccine development could help preparation for the ongoing and future pandemics: 1) Highly sensitive assays help better understand the breadth of cross-reactive immune responses after infection and vaccination. 2) Adjuvants allow vaccine dose sparing and enhance both the magnitude and breadth of responses against vaccine strain and heterologous variants.

\section{DATA AVAILABILITY STATEMENT}

The raw data supporting the conclusions of this article will be made available by the authors, without undue reservation.

\section{ETHICS STATEMENT}

The studies involving human participants were reviewed and approved by The Regional Committee for Medical Research Ethics, Northern Norway and the Norwegian Medicines Agency. The patients/participants provided their written informed consent to participate in this study. The animal study was reviewed and approved by Norwegian Food Safety Authority.

\section{AUTHOR CONTRIBUTIONS}

FZ and RC conceived the project. FZ, GG, and RC designed the experiments. RC and GP conducted the clinical study and collected samples. FZ, LH, and GG conducted the experiments. FZ analyzed the data. FZ, LH, GP, GG, and RC prepared and edited the manuscript. All authors contributed to the article and approved the submitted version.

\section{FUNDING}

This study received intramural funding from the Influenza Center at the University of Bergen and Haukeland University Hospital. The Influenza Center is funded by the University of Bergen, Ministry of Health and Care Services, the Trond Mohn Foundation (TMS2020TMT05), the European Union (EU IMI115672 FLUCOP, H2020 874866 INCENTIVE, H2020 101037867 VACCELERATE, EU IMI 101007799 Inno4Vac) and Nanomedicines Flunanoair (ERA-NETet EuroNanoMed2, JTC2016), and the Research Council of Norway GLOBVAC program (284930).

\section{ACKNOWLEDGMENTS}

We thank all volunteers, clinical staff and staff at the Influenza Center for participation in the study. We thank Crucell Berna Biotech, the Netherlands, for providing the vaccine. We thank Prof. Paul Zhou for providing all the plasmids for $\mathrm{H} 5 \mathrm{~N} 1$ pseudotypes. We thank NIBSC for providing all HPAI H5N1 
antigens used in HI assay. We thank Prof. Florian Krammer for providing the baculoviruses used in purifying $\mathrm{cH} 9 / 5 \mathrm{HA}$ and N1NA proteins. We also thank the staff at the department of comparative medicine at Oslo University Hospital for technical help in association with the mouse experiments.

\section{REFERENCES}

1. WHO. Cumulative Number of Confirmed Human Cases for Avian Influenza A (H5N1) Reported to WHO, 2003-2021. (2021). Available at: https://www.who. int/publications/m/item/cumulative-number-of-confirmed-human-casesfor-avian-influenza-a(h5n1)-reported-to-who-2003-2021-15-april-2021 (Accessed Jun 25, 2021).

2. WHO. Update on Avian Influenza A (H5N1) Virus Infection in Humans. N Engl J Med (2008) 358:261-73. doi: 10.1056/NEJMra0707279

3. WHO. Antigenic and Genetic Characteristics of Zoonotic Influenza Viruses and Development of Candidate Vaccine Viruses for Pandemic Preparedness. Wkly Epidemiol Rec (2014) 89:105-15.

4. WHO. Avian Influenza A (H5N1) Infection in Humans. N Engl J Med (2005) 353:1374-85. doi: 10.1056/NEJMra052211

5. Baz M, Luke CJ, Cheng X, Jin H, Subbarao K. H5N1 Vaccines in Humans. Virus Res (2013) 178:78-98. doi: 10.1016/j.virusres.2013.05.006

6. Matsuda K, Huang J, Zhou T, Sheng Z, Kang BH, Ishida E, et al. Prolonged Evolution of the Memory B Cell Response Induced by a Replicating Adenovirus-Influenza H5 Vaccine. Sci Immunol (2019) 4:eaau2710. doi: 10.1126/sciimmunol.aau2710

7. Ellebedy AH, Krammer F, Li G-M, Miller MS, Chiu C, Wrammert J, et al. Induction of Broadly Cross-Reactive Antibody Responses to the Influenza HA Stem Region Following H5N1 Vaccination in Humans. Proc Natl Acad Sci USA (2014) 111:13133-8. doi: 10.1073/pnas.1414070111

8. Belshe RB, Frey SE, Graham I, Mulligan MJ, Edupuganti S, Jackson LA, et al. Safety and Immunogenicity of Influenza A H5 Subunit Vaccines: Effect of Vaccine Schedule and Antigenic Variant. J Infect Dis (2011) 203:666-73. doi: 10.1093/infdis/jiq093

9. Talaat KR, Luke CJ, Khurana S, Manischewitz J, King LR, McMahon BA, et al. A Live Attenuated Influenza A(H5N1) Vaccine Induces Long-Term Immunity in the Absence of a Primary Antibody Response. I Infect Dis (2014) 209:1860-69. doi: 10.1093/infdis/jiu123

10. Kirkpatrick E, Qiu X, Wilson PC, Bahl J, Krammer F. The Influenza Virus Hemagglutinin Head Evolves Faster Than the Stalk Domain. Sci Rep (2018) 8:10432. doi: 10.1038/s41598-018-28706-1

11. Eichelberger MC, Morens DM, Taubenberger JK. Neuraminidase as an Influenza Vaccine Antigen: A Low Hanging Fruit, Ready for Picking to Improve Vaccine Effectiveness. Curr Opin Immunol (2018) 53:38-44. doi: 10.1016/j.coi.2018.03.025

12. Krammer F, Li L, Wilson PC. Emerging From the Shadow of Hemagglutinin: Neuraminidase Is an Important Target for Influenza Vaccination. Cell Host Microbe (2019) 26:712-13. doi: 10.1016/j.chom.2019.11.006

13. Palese P, Tobita K, Ueda M, Compans RW. Characterization of Temperature Sensitive Influenza Virus Mutants Defective in Neuraminidase. Virology (1974) 61:397-410. doi: 10.1016/0042-6822(74)90276-1

14. DiLillo DJ, Palese P, Wilson PC, Ravetch JV. Broadly Neutralizing AntiInfluenza Antibodies Require Fc Receptor Engagement for. Vivo Protect J Clin Invest (2016) 126:605-10. doi: 10.1172/JCI84428

15. DiLillo DJ, Tan GS, Palese P, Ravetch JV. Broadly Neutralizing Hemagglutinin Stalk-Specific Antibodies Require FcyR Interactions for Protection Against Influenza Virus In Vivo. Nat Med (2014) 20:143-51. doi: 10.1038/nm.3443

16. Cox RJ, Pedersen G, Madhun AS, Svindland S, Saevik M, Breakwell L, et al. Evaluation of a Virosomal H5N1 Vaccine Formulated With Matrix M Adjuvant in a Phase I Clinical Trial. Vaccine (2011) 29:8049-59. doi: 10.1016/j.vaccine.2011.08.042

17. Cox RJ, Major D, Pedersen G, Pathirana RD, Hoschler K, Guilfoyle K, et al. Matrix M H5N1 Vaccine Induces Cross-H5 Clade Humoral Immune Responses in a Randomized Clinical Trial and Provides Protection From Highly Pathogenic Influenza Challenge in Ferrets. PloS One (2015) 10: e0131652. doi: 10.1371/journal.pone.0131652

\section{SUPPLEMENTARY MATERIAL}

The Supplementary Material for this article can be found online at: https://www.frontiersin.org/articles/10.3389/fimmu.2021. 747774/full\#supplementary-material

18. Pedersen GK, Sjursen H, Nostbakken JK, Jul-Larsen A, Hoschler K, Cox RJ. Matrix M(TM) Adjuvanted Virosomal H5N1 Vaccine Induces Balanced Th1/ Th2 CD4(+) T Cell Responses in Man. Hum Vaccin Immunother (2014) 10:2408-16. doi: 10.4161/hv.29583

19. Tsai C, Caillet C, Hu H, Zhou F, Ding H, Zhang G, et al. Measurement of Neutralizing Antibody Responses Against H5N1 Clades in Immunized Mice and Ferrets Using Pseudotypes Expressing Influenza Hemagglutinin and Neuraminidase. Vaccine (2009) 27:6777-90. doi: 10.1016/j.vaccine.2009.08.056

20. Zhou F, Wang G, Buchy P, Cai Z, Chen H, Chen Z, et al. A Triclade DNA Vaccine Designed on the Basis of a Comprehensive Serologic Study Elicits Neutralizing Antibody Responses Against All Clades and Subclades of Highly Pathogenic Avian Influenza H5N1 Viruses. J Virol (2012) 86:6970-78. doi: 10.1128/JVI.06930-11

21. Tete SM, Krammer F, Lartey S, Bredholt G, Wood J, Skrede S, et al. Dissecting the Hemagglutinin Head and Stalk-Specific IgG Antibody Response in Healthcare Workers Following Pandemic H1N1 Vaccination. NPJ Vaccines (2016) 1:16001. doi: 10.1038/npjvaccines.2016.1

22. Islam S, Zhou F, Lartey S, Mohn KGI, Krammer F, Cox RJ, et al. Functional Immune Response to Influenza H1N1 in Children and Adults After Live Attenuated Influenza Virus Vaccination. Scand J Immunol (2019) 90:e12801. doi: $10.1111 /$ sji.12801

23. Szretter KJ, Balish AL, Katz JM. Influenza: Propagation, Quantification, and Storage. Curr Protoc Microbiol (2006) 3:15G.1.1-15G.1.22. doi: 10.1002/ 0471729256.mc15g01s3

24. Dereeper A, Guignon V, Blanc G, Audic S, Buffet S, Chevenet F, et al. Phylogeny.fr: Robust Phylogenetic Analysis for the Non-Specialist. Nucleic Acids Res (2008) 36:W465-9. doi: 10.1093/nar/gkn180

25. Lemoine F, Correia D, Lefort V, Doppelt-Azeroual O, Mareuil F, CohenBoulakia S, et al. NGPhylogeny.fr: New Generation Phylogenetic Services for Non-Specialists. Nucleic Acids Res (2019) 47:W260-5. doi: 10.1093/nar/gkz303

26. WHO. Antigenic and Genetic Characteristics of Zoonotic Influenza A Viruses and Development of Candidate Vaccine Viruses for Pandemic Preparedness. Wkly Epidemiol Rec (2021) 96:88-104.

27. Leroux-Roels I, Borkowski A, Vanwolleghem T, Dramé M, Clement F, Hons E, et al. Antigen Sparing and Cross-Reactive Immunity With an Adjuvanted Rh5n1 Prototype Pandemic Influenza Vaccine: A Randomised Controlled Trial. Lancet (2007) 370:580-89. doi: 10.1016/S0140-6736(07)61297-5

28. Leroux-Roels I, Bernhard R, Gérard P, Dramé M, Hanon E, Leroux-Roels G. Broad Clade 2 Cross-Reactive Immunity Induced by an Adjuvanted Clade 1 Rh5n1 Pandemic Influenza Vaccine. PloS One (2008) 3:e1665. doi: 10.1371/ journal.pone.0001665

29. Nolan TM, Richmond PC, Skeljo MV, Pearce G, Hartel G, Formica NT, et al. Phase I and II Randomised Trials of the Safety and Immunogenicity of a Prototype Adjuvanted Inactivated Split-Virus Influenza A (H5N1) Vaccine in Healthy Adults. Vaccine (2008) 26:4160-67. doi: 10.1016/j.vaccine.2008.05.077

30. Nolan T, Richmond PC, Formica NT, Höschler K, Skeljo MV, Stoney T, et al. Safety and Immunogenicity of a Prototype Adjuvanted Inactivated Split-Virus Influenza A (H5N1) Vaccine in Infants and Children. Vaccine (2008) 26:6383-91. doi: 10.1016/j.vaccine.2008.08.046

31. Andersen Tor K, Zhou F, Cox R, Bogen B, Grødeland G. A DNA Vaccine That Targets Hemagglutinin to Antigen-Presenting Cells Protects Mice Against H7 Influenza. J Virol (2017) 91:e01340-17. doi: 10.1128/JVI.01340-17

32. Alberini I, Del Tordello E, Fasolo A, Temperton NJ, Galli G, Gentile C, et al. Pseudoparticle Neutralization Is a Reliable Assay to Measure Immunity and Cross-Reactivity to H5N1 Influenza Viruses. Vaccine (2009) 27:5998-6003. doi: 10.1016/j.vaccine.2009.07.079

33. Boudreau CM, Yu W-H, Suscovich TJ, Talbot HK, Edwards KM, Alter G. Selective Induction of Antibody Effector Functional Responses Using MF59Adjuvanted Vaccination. J Clin Invest (2020) 130:662-72. doi: 10.1172/ JCI129520 
34. Lovgren Bengtsson K, Morein B, Osterhaus AD. ISCOM Technology-Based Matrix M Adjuvant: Success in Future Vaccines Relies on Formulation. Expert Rev Vaccines (2011) 10:401-03. doi: 10.1586/erv.11.25

35. Venkatraman N, Anagnostou N, Bliss C, Bowyer G, Wright D, LövgrenBengtsson K, et al. Safety and Immunogenicity of Heterologous Prime-Boost Immunization With Viral-Vectored Malaria Vaccines Adjuvanted With Matrix-M ${ }^{\mathrm{TM}}$. Vaccine (2017) 35:6208-17. doi: 10.1016/j.vaccine.2017.09.028

36. Datoo MS, Natama MH, Somé A, Traoré O, Rouamba T, Bellamy D, et al. Efficacy of a Low-Dose Candidate Malaria Vaccine, R21 in Adjuvant MatrixM, With Seasonal Administration to Children in Burkina Faso: A Randomised Controlled Trial. Lancet (2021) 397:1809-18. doi: 10.1016/S0140-6736(21) 00943-0

37. Heath PT, Galiza EP, Baxter DN, Boffito M, Browne D, Burns F, et al. Safety and Efficacy of NVX-CoV2373 Covid-19 Vaccine. N Engl J Med (2021) 385 (13):1172-83. doi: 10.1056/NEJMoa2107659

38. Keech C, Albert G, Cho I, Robertson A, Reed P, Neal S, et al. Phase 1-2 Trial of a SARS-CoV-2 Recombinant Spike Protein Nanoparticle Vaccine. N Engl J Med (2020) 383:2320-32. doi: 10.1056/NEJMoa2026920

39. Hobson D, Curry RL, Beare AS, Ward-Gardner A. The Role of Serum Haemagglutination-Inhibiting Antibody in Protection Against Challenge Infection With Influenza A2 and B Viruses. J Hyg (1972) 70:767-77. doi: $10.1017 /$ s0022172400022610

40. Black S, Nicolay U, Vesikari T, Knuf M, Del Giudice G, Della Cioppa G, et al. Hemagglutination Inhibition Antibody Titers as a Correlate of Protection for Inactivated Influenza Vaccines in Children. Pediatr Infect Dis J (2011) 30:1081-85. doi: 10.1097/INF.0b013e3182367662

41. Nachbagauer R, Wohlbold TJ, Hirsh A, Hai R, Sjursen H, Palese P, et al. Induction of Broadly Reactive Anti-Hemagglutinin Stalk Antibodies by an H5N1 Vaccine in Humans. J Virol (2014) 88:13260-68. doi: 10.1128/JVI.02133-14

42. Jacobsen H, Rajendran M, Choi A, Sjursen H, Brokstad KA, Cox RJ, et al. Influenza Virus Hemagglutinin Stalk-Specific Antibodies in Human Serum Are a Surrogate Marker for In Vivo Protection in a Serum Transfer Mouse Challenge Model. mBio (2017) 8:e01463-17. doi: 10.1128/mBio.01463-17
43. Memoli MJ, Shaw PA, Han A, Czajkowski L, Reed S, Athota R, et al. Evaluation of Antihemagglutinin and Antineuraminidase Antibodies as Correlates of Protection in an Influenza A/H1N1 Virus Healthy Human Challenge Model. mBio (2016) 7:e00417-16. doi: 10.1128/mBio.00417-16

44. Couch RB, Atmar RL, Franco LM, Quarles JM, Wells J, Arden N, et al. Antibody Correlates and Predictors of Immunity to Naturally Occurring Influenza in Humans and the Importance of Antibody to the Neuraminidase. J Infect Dis (2013) 207:974-81. doi: 10.1093/infdis/jis935

45. Monto AS, Petrie JG, Cross RT, Johnson E, Liu M, Zhong W, et al. Antibody to Influenza Virus Neuraminidase: An Independent Correlate of Protection. J Infect Dis (2015) 212:1191-99. doi: 10.1093/infdis/jiv195

46. Krammer F, Weir JP, Engelhardt O, Katz JM, Cox RJ. Meeting Report and Review: Immunological Assays and Correlates of Protection for NextGeneration Influenza Vaccines. Influenza Other Respir Viruses (2020) 14:237-43. doi: 10.1111/irv.12706

Conflict of Interest: The authors declare that the research was conducted in the absence of any commercial or financial relationships that could be construed as a potential conflict of interest.

Publisher's Note: All claims expressed in this article are solely those of the authors and do not necessarily represent those of their affiliated organizations, or those of the publisher, the editors and the reviewers. Any product that may be evaluated in this article, or claim that may be made by its manufacturer, is not guaranteed or endorsed by the publisher.

Copyright (c) 2021 Zhou, Hansen, Pedersen, Grødeland and Cox. This is an openaccess article distributed under the terms of the Creative Commons Attribution License (CC BY). The use, distribution or reproduction in other forums is permitted, provided the original author(s) and the copyright owner(s) are credited and that the original publication in this journal is cited, in accordance with accepted academic practice. No use, distribution or reproduction is permitted which does not comply with these terms. 